\title{
Interactions between melatonin and prolactin during gestation in mink (Mustela vison)
}

\author{
B. D. Murphy, G. B. DiGregorio, D. A. Douglas and A. González-Reyna
}

Reproductive Biology Research Unit, Department of Obstetrics and Gynecology, University of Saskatchewan, Saskatoon, Canada S7N OXO

\begin{abstract}
Summary. Immature female mink, 8 weeks of age in July, were treated with implants releasing melatonin. Mating, which induced ovulation, took place during the normal breeding season in the following March. Circulating prolactin and progesterone concentrations did not undergo the expected gestational increases, and no embryos implanted. A similar absence of gestational changes in prolactin and progesterone values ensued in primiparous mink treated with the melatonin implant 2-3 days after the second of 2 matings. Administration of exogenous sheep prolactin $(0.5 \mathrm{mg} /$ day $)$ by minipump induced precocious elevation of progesterone concentrations in mated mink. Prolactin administration overcame the effects of melatonin, in that the corpora lutea were activated and embryos implanted, but exogenous prolactin resulted in degeneration of implanted embryos both in the presence and absence of chronic melatonin. The results suggest that melatonin has a single effect in alteration of gestation in mink; i.e. the prevention of prolactin secretion. Hyperprolactinaemia may inhibit embryo development in this species.
\end{abstract}

Keywords: melatonin; prolactin; mink; delayed implantation

\section{Introduction}

The phenomenon of delayed implantation in mink was first documented by Hansson (1940). Subsequent work (Hansson, 1947) confirmed that embryonic diapause and luteal quiescence characterized the interval between the arrival of the embryos in the uterus and their consequent attachment and invasion of the uterine stroma. Within the past 10 years considerable advance has been made in the understanding of the endocrine control of delayed implantation in mustelids, including the mink (reviewed by Sundqvist et al., 1988, 1989; Murphy, 1989). In mink, the triggering, but not obligate, stimulus for the induction of implantation is the lengthening of the photoperiod associated with the vernal equinox (Murphy \& James, 1974). Prolactin is the hypophysial product responsible for the initiation of the reactivation of the corpus luteum (CL) and the consequent attachment of the embryo (Papke et al., 1980; Martinet et al., 1980; Murphy et al., 1981). The CL secretes progesterone and other factor(s) essential for embryo implantation (Murphy et al., 1983).

The involvement of photoperiod in the termination of delayed implantation implies a role for the pineal hormone melatonin (Ravault et al., 1986), which has been shown to regulate other lightmediated reproductive events in mammals (reviewed by Ortavant et al., 1985). Pineal denervation during embryonic diapause in mink (Murphy \& James, 1974; Martinet et al., 1983, 1985) and the spotted skunk (May \& Mead, 1986) has been shown to alter the course of gestation and the pattern of secretion of prolactin and progesterone. Duby et al. (1972) first showed that administration of exogenous melatonin during gestation lengthened embryonic diapause and prevented embryo implantation. Studies by Martinet et al. (1983) demonstrated that injection of $100 \mu \mathrm{g}$ melatonin abrogated the increases in circulating concentrations of prolactin and progesterone and prevented implantation in mink. 
Chronic treatment of mink with an implant impregnated with melatonin has been used to induce precocious winter moult (Rose et al., 1984, 1987). The cellular basis for its effect is unknown, but may occur by suppression of prolactin secretion (Rose et al., 1985). As acute treatment with melatonin prevents implantation (Martinet et al., 1983), it was of interest to determine the effects of chronic melatonin treatment on prolactin secretion and associated reproductive sequelae in this species. A further goal was to determine whether the inhibitory effects of melatonin on luteal function and implantation were due solely to inhibition of prolactin secretion, and therefore could be overcome by administration of exogenous prolactin.

\section{Materials and Methods}

\section{Animals and treatments}

Primiparous ranch mink (Mustela vison) of the pastel variety were purchased as juveniles in each year of the experiment from Montgomery Fur Ranch, Wetaskiwin, AB, Canada. Animals were housed outdoors under conditions of environmental photoperiod and temperature throughout the study. Animals were fed daily a complete ration compatible with growth and reproduction. During the breeding season, this ration was supplemented with a mixture containing beef liver, blood meal, eggs, milk products and chicken offal. Fresh water was provided ad libitum. The study was carried out over 3 years. Each female was mated twice during 3-18 March of the year of its participation in the experiment with 7 or more days between matings. All second matings took place between 16 and 18 March. Blood samples were taken by jugular venepuncture or cardiac puncture from animals anaesthetized with ketamine $\mathrm{HCl}(0.4 \mathrm{mg} / \mathrm{kg}$; Rogarsetic, Rogar/STB Montreal, PQ, Canada). Blood samples were taken between 11:00 and 13:00 h on alternate days from 20 March to 1 April of each breeding season and every 5 days thereafter until 20 May, or until termination of the study by laparotomy in animals that were not pregnant. Laparotomies were performed between 21 and 24 April. Date of implantation and age of implanted embryos were estimated from the size of uterine swellings, measured with calipers, or from embryonic characteristics (Murphy \& James, 1974). In the absence of uterine enlargements, the individual horns were flushed with TC199 medium (Gibco, Grand Island, NY, USA) and the flushings examined for the presence of unimplanted embryos. Ovaries from all non-pregnant animals were subjected to histological processing to confirm that ovulation had taken place.

In the first experiment, a group of 7 prepubertal ( $8-10$ weeks of age) female mink received Silastic implants containing $5 \mathrm{mg}$ crystalline melatonin (Wildlife Laboratories, Fort Collins, CO, USA) on 14 July of the year preceding the breeding season of the study. An untreated group of 7 prepubertal mink served as controls. In the second experiment, 5 mink received a $5 \mathrm{mg}$ melatonin implant 1-3 days after the second of 2 matings, and a group of 5 untreated mink served as contemporary controls. In the third experiment, a group of 6 animals received Alzet miniosmotic pumps (Alzet, Palo Alto, CA, USA) which delivered sheep prolactin (NIH-AFP-8277E) at a rate of $0.5 \mathrm{mg} /$ day over 4 weeks. A second group of 6 animals in the same experiment was treated with $5 \mathrm{mg}$ melatonin implants and prolactin infusion of $0.5 \mathrm{mg}$ prolactin/day as described above. Prolactin treatment began on $20 \mathrm{March}, 2-4$ days after the second of 2 matings. A further 6 animals served as the control group. All mink treated during the breeding season were approximately 10 months of age and primiparous.

\section{Radioimmunoassays}

Prolactin. A double-antibody RIA in which purified dog prolactin (AFP-245IB) and antiserum against dog prolactin (AFP-16111778), both kindly donated by Dr A. F. Parlow, was used. The specificity was established by validation studies using mink pituitary extract and mink serum which resulted in parallel displacement of ${ }^{125}$ I-labelled dog prolactin. Sheep prolactin cross-reacts in this assay in a non-parallel manner (A. F. Parlow, personal communication). The intra-assay coefficient of variation, calculated between duplicates of $0 \cdot 39-100 \mathrm{ng}$ dog prolactin/tube, ranged from $2 \cdot 1$ to $9.5 \%$ and the interassay coefficient of variation of one sample assayed at $24 \mathrm{ng} / \mathrm{ml}$ in 4 assays was $33 \cdot 7 \%$.

Progesterone. Progesterone was assayed in $0.1 \mathrm{ml}$ serum samples following hexane extraction and a polyclonal antibody against progesterone (NCR-R 10, provided by Dr N. C. Rawlings) and ${ }^{125}$ I-labelled progesterone (Amersham, Montreal, PQ, Canada) were used. Validation has previously been reported (Rajkumar et al., 1985). The mean extraction efficiency was $74 \%$ and final progesterone concentrations were corrected individually for extraction losses. The intra-assay coefficient of variation on $25-500 \mathrm{pg} /$ tube ranged from 2.4 to $10 \%$. The interassay coefficient of variation on a single sample assayed at $21 \mathrm{ng} / \mathrm{ml}$ progesterone was $16.8 \%$.

\section{Statistical analysis}

Mean \pm s.e.m. values were calculated for hormone concentrations at each bleeding date. Analysis of variance for repeated measures was conducted and individual comparisons were made by Fisher's Least Significant Difference Test (Sokol \& Rohlf, 1985). 


\section{Results}

\section{Effects of chronic melatonin on endocrine and reproductive events}

The incidence of pregnancy in the two control groups, as indicated by the presence of implanted embryos in the uteri of 10 animals and the presence of unimplanted blastocysts in 1 female, was $11 / 12(92 \%)$. The mean ( \pm s.e.m.) number of embryos per female with uterine swellings was $7 \cdot 4 \pm 0 \cdot 8$. It was determined from measurements of uterine swellings and observations of embryos that the mean ( \pm s.e.m.) interval between copulation and implantation was $19 \cdot 5 \pm 0.2$ days and the average date of implantation was 3 April. There was no indication of embryo implantation in any of the mink in the two groups treated with melatonin alone. No embryos were recovered from the uterine flushings of any of these animals. Histological examination of the ovaries of all of the melatonintreated animals revealed that ovulation had occurred, as indicated by the presence of small corpora lutea characteristic of the delay phase of gestation (Hansson, 1947).

Chronic treatment of mink with melatonin implants from July of the previous year or from a few days after the second mating (data not shown) prevented the expected rise in prolactin which occurred late in March in the control animals (Fig. 1). There was a consequent absence of reactivation of the CL following both short- and long-term treatment with melatonin as indicated by the size of the $\mathrm{CL}(<1.0 \mathrm{~mm}$ in diameter $)$ in the ovaries and the absence of the expected increase in circulating progesterone (Fig. 2b).

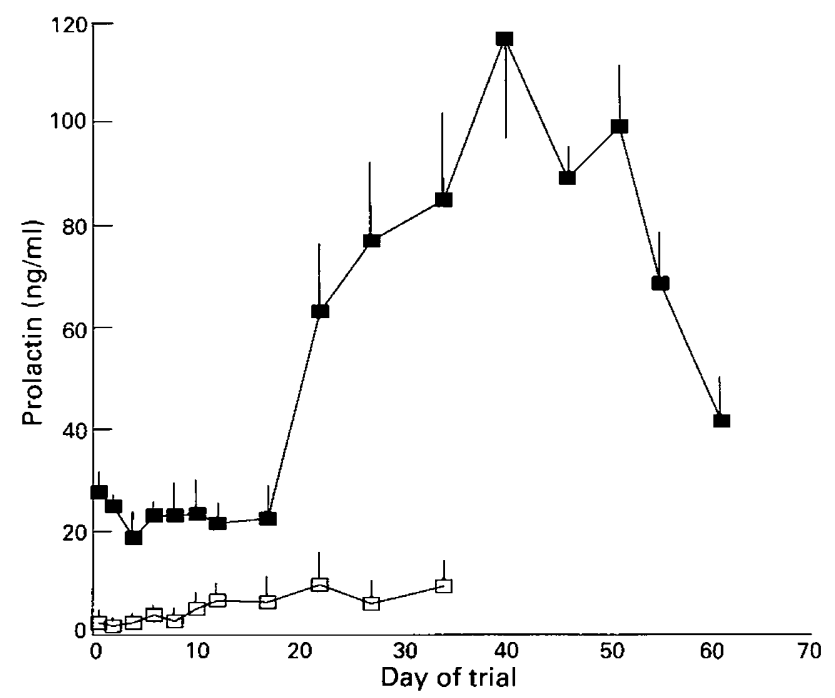

Fig. 1. Mean ( \pm s.e.m.) serum prolactin concentrations in control (-口-) mink and mink treated with $5 \mathrm{mg}$ melatonin implants $(-\square-)$ initiated on 14 July of the previous year when animals were approximately 8 weeks of age. Day $0=20$ March. $\mathrm{N}=7$ for each group.

\section{Effects of prolactin on endocrine events and gestation}

Infusion of prolactin elevated the serum concentrations of this hormone beginning a few days after initiation of treatment (Fig. 3). These results are not strictly quantitative, as sheep prolactin does not displace dog prolactin from antiserum AFP-1611778 in a parallel fashion (A. F. Parlow, personal communication). However, exogenous prolactin induced early activation of the $\mathrm{CL}$ as indicated by precocious progesterone increases which were in excess of control values from Days 5 to 10 (Fig. 2a) and of melatonin only-treated animals (Fig. 2b) from Days 5 to 20 after application 
of the minipump delivering prolactin $(P<0.05)$. In both prolactin-treated groups, progesterone concentrations had declined significantly relative to controls by 16 days after initiation of minipump infusion $(P<0.01$, Figs $2 \mathrm{a}, 2 \mathrm{~b})$. This decline occurred in spite of infusion of prolactin on 12 further days and the presence of intact pituitary glands.

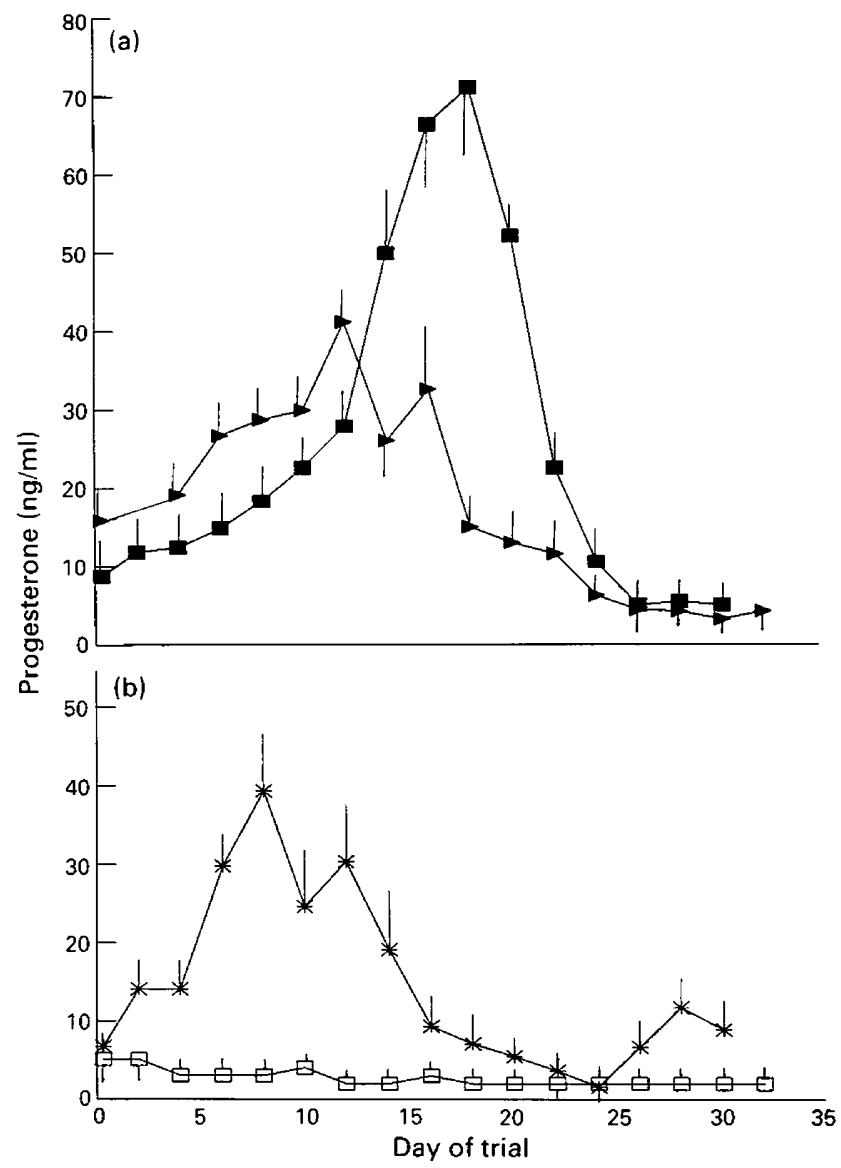

Fig. 2. Mean ( \pm s.e.m.) serum progesterone concentrations from 20 March through 22 April in female mink (a) untreated (,$- N=6$ ) or subjected to infusion of $0.5 \mathrm{mg}$ sheep prolactin per day for 28 days $(\longrightarrow-, N=6)$, and (b) treated with an implant releasing melatonin $2-4$ days after the second of two matings $(-\square-, \mathrm{N}=5$ ) or a melatonin implant and accompanied by infusion of $0.5 \mathrm{mg}$ sheep prolactin per day for 28 days $\left(-_{*}-, \mathrm{N}=6\right.$ ). Animals were mated twice between 3 and 18 March and treatments were started on 20 March (Day 0).

Uterine swellings were present in $83 \%(5 / 6)$ of the mink treated with prolactin only. The mean number of uterine swellings per female was $6 \cdot 2 \pm 1 \cdot 3$. Prolactin overcame the inhibitory effects of chronic melatonin treatment, as evidenced by implanted embryos in $5 / 6$ of the mink bearing melatonin implants that were subsequently treated with prolactin. The mean number of uterine swellings was $5.4 \pm 1 \cdot 4$. No embryos were recovered from the single mink in either group in which no implantation sites were present. There was no statistical difference in the numbers of embryos implanted between control and treated mink. In both of the prolactin-treated groups, the uterine swellings were spaced more closely in some animals and were oblong rather than characteristically round as found in the control animals. Consequent gross and histological examination indicated 


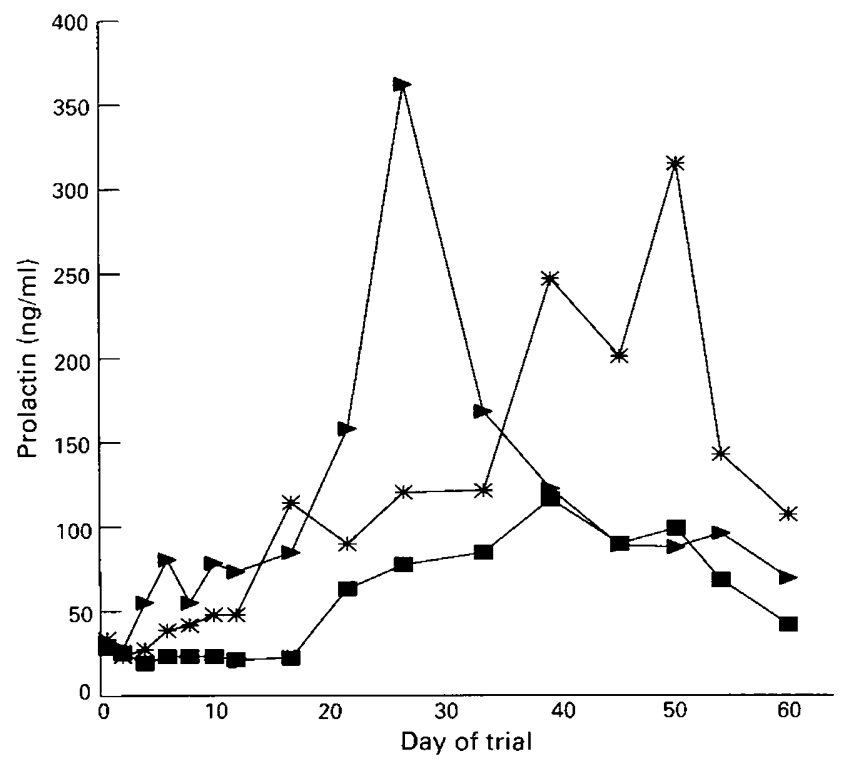

Fig. 3. Mean serum prolactin concentrations in mink from 20 March (Day 0) to 20 May. The groups received no treatment ( $-\mathrm{E}, \mathrm{N}=5$ ), minipump infusion of $0.5 \mathrm{mg}$ sheep prolactin per day $(\longrightarrow-, \mathrm{N}=6$ ), or a $5 \mathrm{mg}$ melatonin implant plus $0.5 \mathrm{mg}$ sheep prolactin per day $(-*-, N=6)$.

that implanted embryos were present and that degeneration had taken place. The degeneration rendered determination of date of implantation by size of uterine swellings or embryonic characteristics invalid.

\section{Discussion}

Chronic treatment with melatonin did not interfere with mating, as indicated by observation of copulation in mink bearing implants. The presence of CL in the ovaries of mink chronically treated with melatonin demonstrated that ovulation had also occurred in these animals. The animals in one group of this study were first treated as 8 -week-old kits. The results therefore suggest that exogenous melatonin did not affect the process of puberty in the female of this species.

Chronic melatonin treatment had profound effects on the course of mink gestation. The expected increases in prolactin (Martinet et al., 1983) and progesterone (Murphy \& Moger, 1977) did not occur in animals that had been treated with melatonin either for a period of 8 months before the breeding season or after the second mating. No embryos implanted in these animals, and none could be recovered by flushing of the uteri. The results of the present study confirm the reports of others which have shown that injection of melatonin interfered with prolactin (Martinet et al., 1983, 1985) and progesterone (Duby et al., 1972) secretion.

An influence of photoperiod has been demonstrated on both the onset of progesterone secretion (Allais \& Martinet, 1978) and the occurrence of embryo implantation in mink (Murphy \& James, 1974). Melatonin is accepted as the principal mediator of photoperiodic events, and higher concentrations and longer periods of secretion are associated with short days in mammals. Denervation of the pineal gland, the source of melatonin in mammals, eliminates the synchronizing influence of photoperiod on delayed implantation in mink (Martinet et al., 1985). Taken together, published reports and the results of the present investigation are consistent with the view that photoperiod and the pineal modulate the length of preimplantation delay in mink by melatonin secretion. 
This study addressed the mechanism(s) by which melatonin exerts its regulatory effects on delayed implantation. It had been previously shown that injection of exogenous bovine prolactin to intact (Martinet et al., 1980; Papke et al., 1980) or hypophysectomized (Murphy et al., 1981) mink resulted in activation of the $\mathrm{CL}$ and consequent embryo implantation. In the present study, similar results were achieved when sheep prolactin was delivered by means of minipump infusion. The most significant finding of this study is that minipump delivery of sheep prolactin reversed the effects of chronic melatonin treatment and resulted in activation of the CL, progesterone secretion and embryo implantation. Sheep prolactin increases the accumulation of progesterone by mink luteal cells in vitro (Murphy et al., 1984), and it is believed that the observed responses are direct effects of prolactin on the ovary. These results suggest that the sole effect of melatonin in preventing the cascade of events that culminates in implantation in mink is the abrogation of prolactin secretion.

The implanted embryos were degenerate in the animals treated with prolactin in the presence or absence of a melatonin implant. In addition, embryo spacing within the uteri was inappropriate in animals in which prolactin had been infused. The decline in progesterone concentrations in animals treated with prolactin following 18 days of prolactin infusion suggests that loss of luteal support may have been responsible for embryo degeneration. As Rose et al. (1983) reported binding of prolactin to the mink uterus, an alternative hypothesis is that exogenous prolactin, presumably present in excess, may have affected uterine growth or secretion and/or embryo spacing or development. The relation of this phenomenon to embryonic mortality in mink merits further experimentation.

Funds for this study were acquired from a Natural Sciences and Engineering Research Council Grant, A9743, to B.D.M. G.B.D. was supported by a scholarship from the College of Graduate Studies and Research, University of Saskatchewan. We thank Sharron Johannesen for technical assistance; Dr A. F. Parlow, Harbor General Hospital, Torrance, CA, for prolactin assay materials; and Dr N. C. Rawlings, University of Saskatchewan, for antiserum against progesterone.

\section{References}

Allais, C. \& Martinet, L. (1978) Relation between daylight ratio, plasma progesterone levels and timing of nidation in mink (Mustela vison). J. Reprod. Fert. 54, 133-136.

Duby, R.T., Pilbeam, T. \& Travis, H.F. (1972) The influence of melatonin and hysterectomy on plasma progesterone levels of the mink (Mustela vison). Biol. Reprod. 7, 125, abstr.

Hansson, A. (1940) Undersokninger av minkens fortplantningforhallanden. Vara Palsdjur. 11, 290-296.

Hansson, A. (1947) The physiology of reproduction in mink (Mustela vison, Schreb.) with special reference to delayed implantation. Acta zool. Stockholm 28, 1-136.

Martinet, L., Allais, C. \& Allain, D. (1980) The role of prolactin and LH in luteal function and blastocyst growth in mink (Mustela vison). J. Reprod. Fert., Suppl. 29, 119-130.

Martinet, L., Allain, D. \& Mernier, M. (1983) Regulation in pregnant mink (Mustela vison) of plasma progesterone and prolactin concentrations and regulation of the onset of the spring moult by daylight ratio and melatonin injections. Can. J. Zool. 61, 1959-1963.

Martinet, L., Allain, D. \& Chabi, Y. (1985) Pineal denervation by cervical sympathetic ganglionectomy suppresses the role of photoperiod on pregnancy or pseudopregnancy, body weight and moulting periods in the mink (Mustela vison). J. Endocr. 107, 31-39.

May, R. \& Mead, R.A. (1986) Evidence for pineal involvement in the timing of implantation in the western spotted skunk. J. Pineal Res. 3, 1-8.

Murphy, B.D. (1989) Reproductive physiology of female mustelids. In Reproductive Biology of Black-footed Ferrets, pp. 107-123. Ed. U. S. Seal. Yale Univ. Press, New Haven.

Murphy, B.D. \& James, D.A. (1974) The effects of light and sympathetic innervation to the head on nidation in mink $J$. exp. Zool. 187, 267-276.

Murphy, B.D. \& Moger, W.H. (1977) Progestins of mink gestation: the effects of hypophysectomy. Endocr. Res. Commun. 4, 45-60.

Murphy, B.D., Concannon, P.W., Travis, H.F. \& Hansel, W. (1981) Prolactin: the hypophyseal factor that terminates embryonic diapause in mink. Biol. Reprod. 25, 487-491.

Murphy, B.D., Mead, R.A. \& McKibbin, P.E. (1983) Luteal contribution to the termination of preimplantation delay in mink. Biol. Reprod. 28, 497-503.

Murphy, B.D., Rajkumar, K. \& Silversides, D.W. (1984) Luteotrophic control of the mink corpus luteum Downloaded from Bioscientifica.com at 04/26/2023 01:36:58PM 
during the postimplantation phase of gestation. Proc. 3rd Int. Cong. Fur Anim. Prod., Versailles, Abstr. 32.

Ortavant, R., Pelletier, J., Ravault, J.P., Thimonien, J. \& Volland-Nart, P. (1985) Photoperiod: main proximal and distal factors of the circannual cycle of reproduction in farm mammals. Oxford Rev. Reprod. Biol. 7, 305-345.

Papke, R.L. Concannon, P.W., Travis, H.F. \& Hansel, W. (1980) Control of luteal function and implantation in the mink by prolactin. J. Anim. Sci. 50, 1102-1107.

Rajkumar, K., Malinek, J. \& Murphy, B.D. (1985) Effect of lipoproteins and luteotropins on progesterone accumulation by luteal cells from the pregnant pig. Steroids 45, 119-134.

Ravault, J.P., Martinet, L., Bonneford, C., Claustrate, B. \& Brun, J. (1986) Diurnal variations of plasma melatonin concentrations. J. Pineal Res. 3, 365-373.

Rose, J., Stormshak, F., Adair, J. \& Oldfield, J. (1983) Prolactin binding sites in the uterus of the mink. Molec. cell. Endocr. 31, 131-139.
Rose, J., Stormshak, F., Oldfield, J. \& Adam, J. (1984) Induction of winter fur growth in mink (Mustela vison) with melatonin. J. Anim. Sci. 58, 57-61.

Rose, J., Stormshak, F., Oldfield, J. \& Adair, J. (1985) The effects of photoperiod and melatonin on serum prolactin levels of mink during the autumn moult. $J$. Pineal Res. 2, 13-19.

Rose, J., Oldfield, J. \& Stormshak, F. (1987) Apparent role of melatonin and prolactin in initiating winter fur growth in mink. Gen. comp. Endocrinol. 65, $212-215$.

Sokol, R.R. \& Rohlf, F.J. (1985) NESTAN. Supplement to Biometry, 2nd edn W.H. Freeman, New York.

Sundqvist, C., Ellis, L.C. \& Bartke, A. (1988) Reproductive endocrinology of the mink (Mustela vison). Endocr. Rev. 9, 247-266.

Sundqvist, C., Amador, A.G. \& Bartke, A. (1989) Reproduction and fertility in the mink. J. Reprod. Fert. 85, 413-441.

Received 28 July 1989 